\title{
Association Between Nutritional Risk Screening Score and Prognosis of Patients with Sepsis
}

\author{
Qiqing Gao* \\ Yao Cheng* \\ Zhuohong Li (iD \\ Qingyun Tang \\ Rong Qiu \\ Shaohang Cai $\mathbb{D}$ \\ Xuwen Xu (D) \\ Jie Peng \\ Hongyan Xie
}

Department of Infectious Diseases, Nanfang Hospital, Southern Medical University, Guangzhou, Guangdong

Province, People's Republic of China

*These authors contributed equally to this work
Correspondence: Jie Peng; Hongyan Xie Department of Infectious Diseases, Nanfang Hospital, Southern Medical University, Guangzhou, Guangdong,

510515, People's Republic of China

Tel +862062787428

Fax +862087719653

Email pjiel38@163.com;

492577598@qq.com
Background: Malnutrition is one of the most critical factors affecting patients' risk of infection and length of stay, and it may affect the prognosis of patients with sepsis. There have been no studies that have applied nutritional risk screening tools to stratify patients with sepsis according to prognosis.

Methods: We retrospectively analyzed the clinical data of 425 adult sepsis inpatients who were grouped based on nutritional risk screening (NRS) score, including a nutrition score, disease severity score, and age score. Prognostic factors were analyzed using univariate and multivariate regression analyses.

Results: Of the enrolled patients, 174 had an NRS score of $\geq 3$; these patients were older and had a longer hospitalization time but lower body mass index (BMI), albumin (ALB) than others. Univariate Cox regression analysis showed that age, ALB, C-reactive protein (CRP), and NRS score were significantly $(\mathrm{P}<0.05)$ associated with in-hospital mortality. Multivariate analysis showed that age (hazard ratio $[\mathrm{HR}]=1.020$, 95\% confidence interval $[\mathrm{CI}]$ : $1.005-$ 1.036; $\mathrm{P}=0.008)$ and $\mathrm{ALB}(\mathrm{HR}=0.924,95 \% \mathrm{CI}: 0.885-0.966 ; \mathrm{P}<0.001)$ were independent risk factors for sepsis-related mortality. The Kaplan-Meier analysis revealed that the cumulative in-hospital mortality of sepsis patients with an NRS score of $\geq 3$ was significantly higher than that of patients with an NRS score of $<3(\mathrm{P}=0.022)$.

Conclusion: NRS scores can effectively risk stratify sepsis patients. Patients with high NRS scores should be monitored more closely to halt further disease progression.

Keywords: sepsis, malnutrition, NRS, risk stratification, prognostic assessment

\section{Introduction}

Sepsis is a disease with a high mortality, ${ }^{1,2}$ as it can easily progress to septic shock and death. It is estimated that there are 30 million cases of sepsis worldwide each year resulting in more than 8 million deaths. ${ }^{3}$ Although early diagnosis and treatment of sepsis have improved, the mortality rate remains above $15 \%$ and is as high as $50 \%$ when septic shock occurs. ${ }^{4,5}$ Early identification and management of high-risk sepsis patients can decrease the burden on health services and long-term mortality rates, but is clinically challenging. ${ }^{6-8}$ Delayed treatment may result in septic shock and/or refractory multi-organ failure, the leading cause of death in sepsis. The 2016 Surviving Sepsis Campaign (SSC) international guidelines for managing sepsis and septic shock recommend immediate initiation of treatment and resuscitation. ${ }^{9}$ This spectrum of care bundle includes measurement of lactate levels, microbiology cultures, early antimicrobial therapy, and efficient fluid resuscitation. Malnutrition is an important contributor to mortality in patients with sepsis, ${ }^{10,11}$ who are in a prolonged state of high stress and severe catabolism and are thus more 
prone to malnutrition, reduced immunity, and organ dysfunction, all of which worsen their prognosis. ${ }^{12}$ On the other hand, the so-called obesity paradox is that sepsis patients who are obese have lower mortality than those who are not obese ${ }^{13-16}$ for reasons that are unclear.

Nutritional Risk Screening (NRS) is an instrument for assessing nutritional risk for hospital inpatients recommended by the European Society of Parenteral and Enteral Nutrition (ESPEN) in 2002. ${ }^{17}$ The Society of Critical Care Medicine (SCCM) and the American Society for Parenteral and Enteral Nutrition (ASPEN) also recommended the use of NRS-2002 for the screening of nutritional risk and disease severity in critically ill patients. ${ }^{18}$ NRS-2002 evaluates nutritional impairment based on recent changes in BMI, weight, and food intake; disease severity is determined by evaluating nutritional status in the context of recent medical history (eg, fracture, surgery, tumor, hemodialysis, and intensive care treatment) and chronic diseases (eg, metabolic disorder). NRS-2002 is a nutritional screening tool widely used in adult inpatients that has high sensitivity and specificity and is easier to use. $^{19}$ Some studies have shown that NRS-2002 is a valuable independent risk score for malnutritionassociated mortality and poor clinical outcome in inpatients. $^{20-22}$

Patients with sepsis are at higher risk of acute diseaseor injury-related malnutrition. Applying appropriate nutritional screening tools to patients with sepsis could improve clinical outcomes through the early implementation of appropriate management strategies. ${ }^{23,24}$ However, to date, there have been no studies in which patients with sepsis were stratified according to nutritional risk. To this end, we evaluated the utility of the NRS score for predicting the prognosis of in-hospital patients with sepsis in a large cohort in this study.

\section{Subjects and Methods Subjects}

In this retrospective study, we obtained data of patients diagnosed with sepsis through electronic medical records, from January 2018 to December 2019 at Nanfang Hospital of Southern Medical University (Guangzhou, China). Inclusion criteria were as follows: 1) age $\geq 18$ years; and 2) diagnosed with sepsis following the $3 \mathrm{rd}$ International Consensus Definitions for Sepsis and Septic Shock. ${ }^{25}$ Exclusion criteria were as follows: 1) diagnosed with congenital malnutrition or related diseases; 2) HIV infection; and 3) incomplete/missing clinical data. The flow chart of the study protocol is shown in Figure 1. This retrospective study was approved by the Institutional Review Board/Independent Ethics Committee of Nanfang Hospital of Southern Medical University, and the need for informed consent was waived since all data were anonymized. Patient privacy and confidentiality of data were maintained in accordance with the Declaration of Helsinki.

\section{Data Collection and NRS Assessment}

Demographic and clinical data included sex, age, height, body weight, medical history, hospitalization time, white blood cell count (WBC), lymphocyte count (LYM), hemoglobin (HB), C-reactive protein (CRP), procalcitonin (PCT), albumin (ALB), total protein (TP), major comorbidities, source of infection, antimicrobial treatment condition, and sequential organ failure assessment (SOFA) score. Body mass index (BMI) was calculated based on the patient's height and weight measured on admission. NRS score was calculated based on NRS-2002, ${ }^{17}$ which includes age, undernutrition, and disease severity with a total score of $0-7$, where the "nutrition score" ranges from 0 to 3 and the "disease severity score" ranges from 0 to 3 . The disease severity assessment criteria included hip fracture, chronic diseases (diabetes, cirrhosis, chronic obstructive pulmonary disease, and hemodialysis), abdominal surgery, stroke, craniocerebral trauma, severe pneumonia, bone marrow transplantation, and admission to the intensive care unit. Parameters for assessing impaired nutritional status were changes in BMI, percentage of recent weight loss, and food intake. Additionally, 1 point was given for age $\geq 70$ years. Patients with an NRS score of $\geq 3$ are considered at high nutritional risk on hospital admission.

\section{Statistical Analysis}

Continuous variables are expressed as mean \pm standard error and were compared with the Student's $t$-test. One-way ANOVA was used for multiple group comparisons. Categorical variables are expressed as a number (percentage) and were compared with the Chi-squared test. Univariate and multivariate Cox regression analyses were carried out and the results are presented as hazard ratios (HRs) with $95 \%$ confidence intervals (CIs). The Kaplan-Meier survival method was used to analyze the cumulative survival rate of patients with sepsis and the Log rank test was used for intergroup 


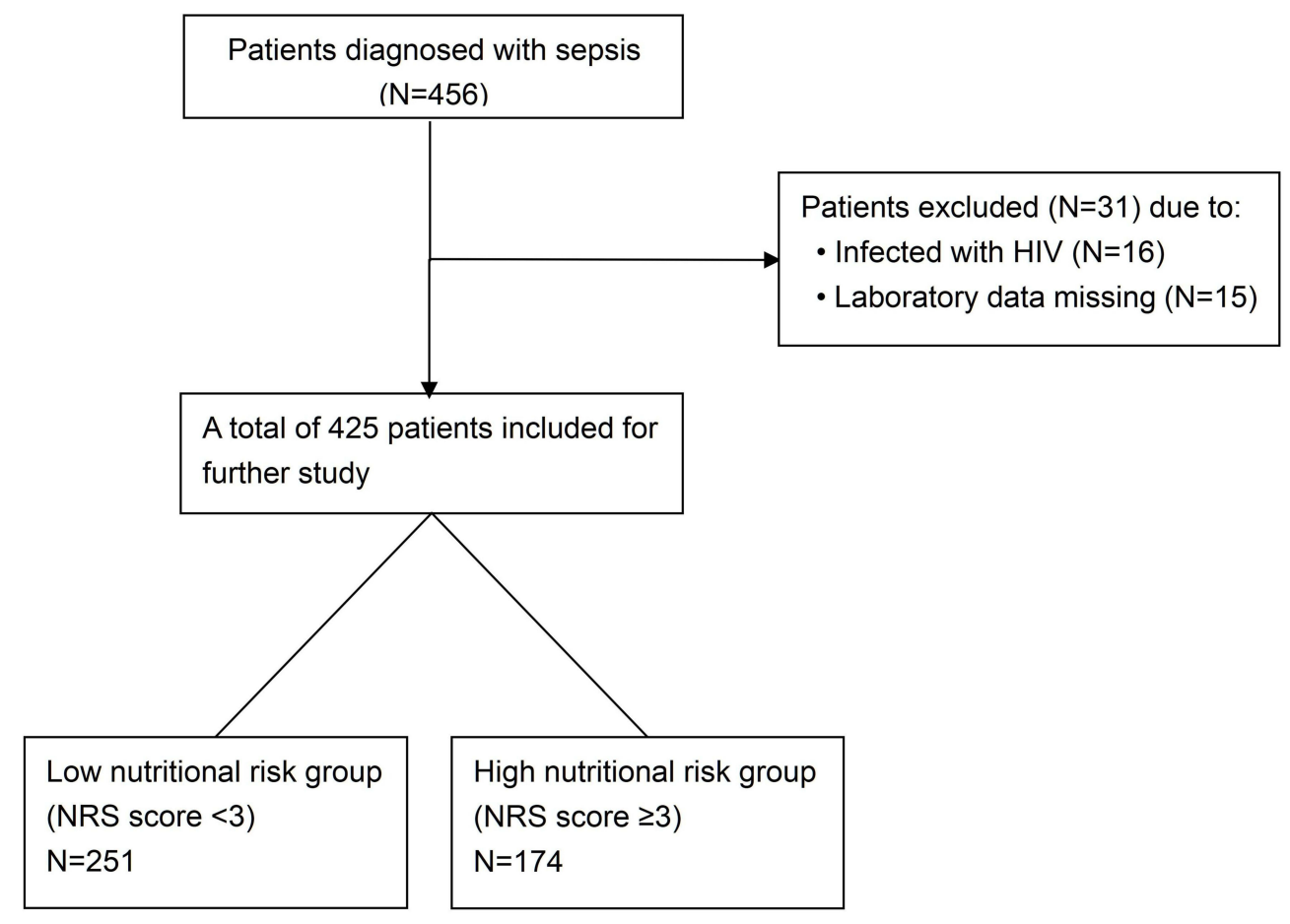

Figure I Flow chart of the two phases in the study.

comparisons. All analyses were performed using SPSS v21.0 and GraphPad Prism 6.0 with an alpha level of 0.05 .

\section{Results}

\section{Clinical Characteristics of Patients with Sepsis Grouped by NRS Score}

A total of 425 patients with sepsis were included in our study.

The average age of the patients was $43.7 \pm 17.3$ years and 281 (66.1\%) were male. The patients were divided into 2 groups according to NRS score as followed: NRS score $<3$ ( $N=251$, low nutritional risk group) and score $\geq 3$ ( $N=174$, high nutritional risk group). The high nutritional risk group was older ( $\mathrm{P}=0.005)$, had lower BMI $(\mathrm{P}<0.001)$, lower ALB $(\mathrm{P}<0.001)$, lower HB $(\mathrm{P}<0.001)$, higher serum CRP $(\mathrm{P}=0.048)$, longer hospitalization time $(\mathrm{P}<0.001)$, and higher SOFA score $(\mathrm{P}<0.001)$ compared to the low nutritional risk group (Table 1).

\section{Relationship Between BMI, ALB Levels, and NRS Score}

To evaluate the relationship between nutritional risk and clinical parameters, we compared BMI and serum ALB levels in patients with different NRS scores (points 0 to 5).
Lower BMI and ALB levels were associated with a higher NRS score (both $\mathrm{P}<0.001$; Figure 2).

\section{Relationship Between NRS Score and Clinical Outcome}

Further prognostic analysis was performed in 372 patients with sepsis who had complete survival data. Of the 372 patients, 308 survived and 64 died. There were significant differences in the proportions of surviving or non-surviving patients in the subgroups with different NRS scores $(\mathrm{P}=0.020 ;$ Figure 3$)$. We therefore performed a Kaplan-Meier analysis and found that the cumulative inhospital survival rate of sepsis patients with an NRS score of $\geq 3$ (high nutritional risk group) was significantly lower than that of patients with an NRS score of $<3$ (low nutritional risk group) ( $\mathrm{P}=0.022$; Figure 4$)$.

\section{Univariate and Multivariate Analysis of Factors Associated with Prognosis of Sepsis Patients}

Univariate Cox regression analysis showed that age, ALB, $\mathrm{CRP}$, and NRS scores were significantly $(\mathrm{P}<0.05)$ associated with in-hospital mortality. Multivariate analysis showed that age $(\mathrm{HR}=1.020,95 \%$ CI: $1.005-1.036$; 
Table I Basic Clinical Data of Sepsis Patients in Different NRS Score Groups

\begin{tabular}{|c|c|c|c|c|}
\hline \multirow[t]{2}{*}{ Variable } & \multirow[t]{2}{*}{ Total } & \multicolumn{2}{|c|}{ Nutritional Risk Screening Score } & \multirow[t]{2}{*}{$P$ value } \\
\hline & & $<3$ & $\geq 3$ & \\
\hline Sample size, $N$ & 425 & 251 & 174 & \\
\hline Gender, male, $N(\%)$ & $28 I(66.1)$ & $174(69.3)$ & $107(6 \mid .5)$ & 0.094 \\
\hline Age, years & $43.7 \pm 17.3$ & $42.5 \pm 17.1$ & $47.8 \pm 17.9$ & 0.005 \\
\hline BMI, $\mathrm{kg} / \mathrm{m}^{2}$ & $21.8 \pm 3.9$ & $23.0 \pm 3.7$ & $20.8 \pm 3.8$ & $<0.001$ \\
\hline Hospitalization time, days & $13.2 \pm 9.7$ & $11.1 \pm 7.6$ & $|6.4 \pm| 1.4$ & $<0.001$ \\
\hline \multicolumn{5}{|l|}{ Major comorbidities, N(\%) } \\
\hline Hypertension & $14(3.3)$ & $6(2.4)$ & $8(4.6)$ & 0.210 \\
\hline Diabetes & $21(4.9)$ & $14(5.6)$ & $7(4.0)$ & 0.467 \\
\hline Kidney failure & $42(9.9)$ & $17(6.8)$ & $25(\mid 4.4)$ & 0.010 \\
\hline Source of infection, $N(\%)$ & & & & 0.126 \\
\hline Respiratory infections & $128(30.1)$ & $65(25.9)$ & $63(36.2)$ & \\
\hline Urinary infections & $38(8.9)$ & $24(9.6)$ & $14(8.0)$ & \\
\hline Biliary infections & $18(4.2)$ & $9(3.6)$ & $9(5.2)$ & \\
\hline Bloodstream infections & $124(29.2)$ & $82(32.7)$ & $42(24.1)$ & \\
\hline Others or unexplained sources & $117(27.5)$ & 7I(28.3) & $46(26.4)$ & \\
\hline ALB, $g / L$ & $36.6 \pm 6.3$ & $39.3 \pm 5.1$ & $32.5 \pm 5.4$ & $<0.001$ \\
\hline $\mathrm{TP}, \mathrm{g} / \mathrm{L}$ & $67.8 \pm 8.6$ & $69.2 \pm 7.1$ & $64.5 \pm 9.2$ & $<0.001$ \\
\hline $\mathrm{HB}, \mathrm{g} / \mathrm{L}$ & $113.7 \pm 25.2$ & $122.2 \pm 22.6$ & $99.2 \pm 23.5$ & $<0.001$ \\
\hline WBC, $\times 10^{9} / \mathrm{L}$ & $11.1 \pm 51.6$ & $13.2 \pm 69.7$ & $9.7 \pm 6.6$ & 0.549 \\
\hline LYM, $\times 10^{9} / \mathrm{L}$ & $1.6 \pm 1.5$ & $1.7 \pm 1.8$ & $1.4 \pm 1.0$ & 0.030 \\
\hline CRP, mg/L & $64.8 \pm 67.1$ & $61.5 \pm 66.9$ & $76.1 \pm 70.6$ & 0.048 \\
\hline PCT, ng/mL & $2.6 \pm 16.5$ & $1.5 \pm 5.7$ & $5.0 \pm 27.0$ & 0.135 \\
\hline SOFA score & $3.1 \pm 1.8$ & $2.9 \pm 1.6$ & $3.7 \pm 2.1$ & $<0.001$ \\
\hline Nutrition support, $\mathrm{N}(\%)$ & $144(33.9)$ & $86(34.3)$ & $58(33.3)$ & 0.842 \\
\hline
\end{tabular}

Abbreviations: NRS, nutritional risk screening; BMI, body mass index; ALB, albumin; TP, total protein; HB, hemoglobin; WBC, white blood cell count; LYM, lymphocyte count; CRP, C-reactive protein; PCT, procalcitonin; SOFA, sequential organ failure assessment.

$\mathrm{P}=0.008)$ and ALB $(\mathrm{HR}=0.924,95 \% \mathrm{CI}: 0.885-0.966$; $\mathrm{P}<0.001)$ were independent risk factors for mortality in patients with sepsis (Table 2).

\section{Discussion}

The results of this study demonstrate that older age and lower ALB levels are independent risk factors for adverse prognosis in sepsis patients. Additionally, patients at high nutritional risk (NRS score $\geq 3$ ) had a significantly higher cumulative in-hospital mortality rate. These results can help stratify patients with sepsis according to prognosis. Based on our findings, timely interventions, such as nutritional assessment and support, are needed for sepsis patients with a higher NRS score.

NRS-2002 is a nutritional screening tool widely used in adult inpatients with high sensitivity and specificity. The NRS-2002 covers age, recent nutritional status, and disease severity and can effectively identify individuals at high nutritional risk or poor nutritional status. Patients with a total NRS score of $\geq 3$ are considered to be at high nutritional risk and require nutritional support, while weekly nutritional risk screening is recommended for those with a score of $<3 .{ }^{17,26}$ Sepsis is a complex condition that can rapidly progress to death. Sepsis patients are in 
A

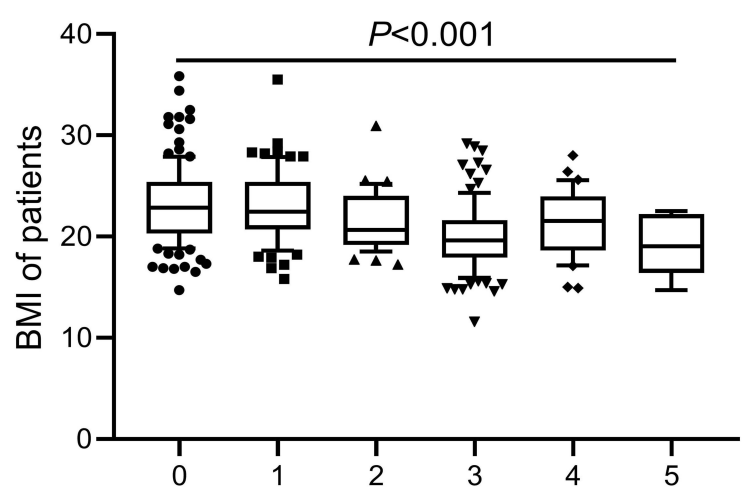

Nutritional Risk Screening score
B

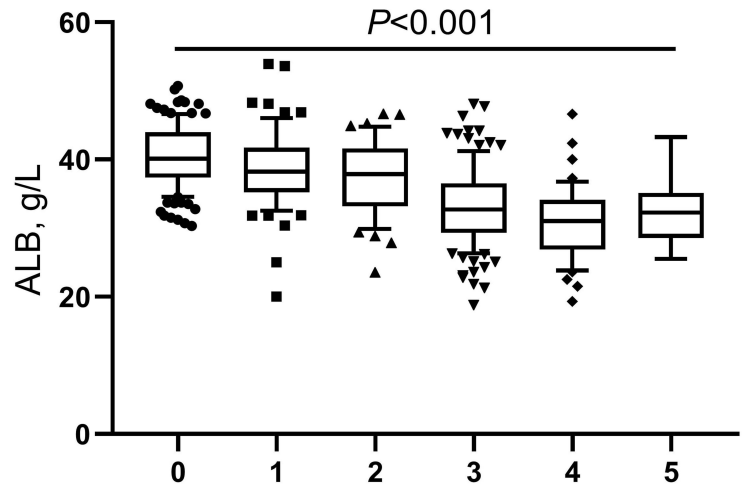

Nutritional Risk Screening score

Figure $2 \mathrm{BMI}$ and ALB in different nutritional risk screening score subgroups. (A) There were statistically significant differences in BMI among the six subgroups with different NRS scores $(23.2 \pm 3.9$ vs $22.9 \pm 3.6$ vs $21.5 \pm 2.9$ vs $19.9 \pm 3.8$ vs $21.2 \pm 3.4$ vs $19.1 \pm 3.1, P<0.001)$. (B) There were statistically significant differences in $A$ LB among the six subgroups with different NRS scores $(40.3 \pm 4.5$ vs $38.6 \pm 5.6$ vs $37.6 \pm 5.4$ vs $33.4 \pm 5.8$ vs $31.1 \pm 5.5$ vs $32.6 \pm 5.2$, $P<0.00 I)$.

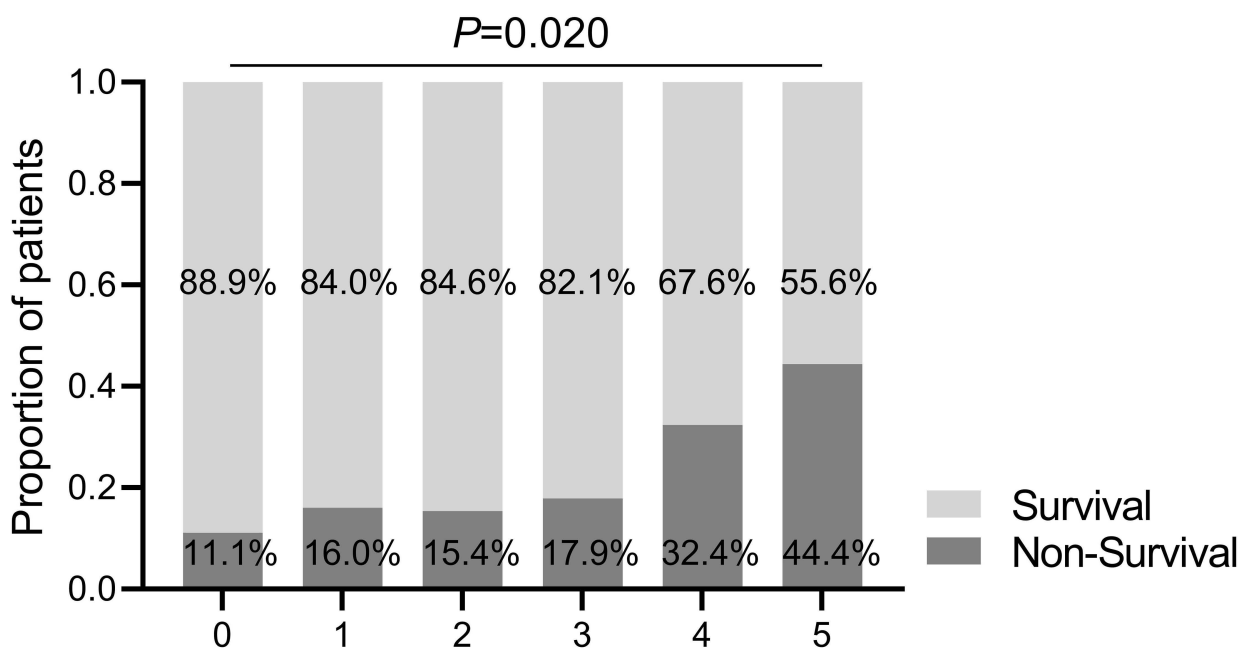

\section{Nutritional Risk Screening score}

Figure 3 Clinical outcomes in different nutritional risk screening score subgroups. The composition of survivors in hospitalized patients with sepsis was statistically different across the six subgroups with various NRS scores ( $88.9 \%$ vs $84.0 \%$ vs $84.6 \%$ vs $82.1 \%$ vs $67.6 \%$ vs $55.6 \%, \mathrm{P}=0.020)$.

a state of sustained immune activation or inhibition and often exhibit an excessive inflammatory response accompanied by disordered metabolism of macronutrients such as carbohydrates, proteins, and lipids, ${ }^{27}$ which increases the risk of malnutrition. ${ }^{28}$ Dysregulation of metabolic pathways and severe energy deficiency caused by infections can lead to poor clinical outcomes. ${ }^{29-31}$ Nutritional support is considered indispensable for the treatment of sepsis to improve metabolic balance and alleviate adverse outcomes related to diseases. ${ }^{32,33}$ The 2016 SSC international guidelines stated that the management of patients with sepsis is multisystemic and multifaceted, including nutritional support, and that inadequate nutritional intake may lead to immune hyporesponsiveness and an increase in infectious complications. ${ }^{9}$ Therefore, it is critical that clinicians assess the nutritional risk of patients with sepsis.

We found that survival rates differed significantly between sepsis patients with an NRS score of $<3$ (low nutritional risk group) and those with a score of $\geq 3$ (high nutritional risk group). In our study, as in others, malnutrition was associated with an increased risk of adverse clinical outcome. ${ }^{34}$ Adejumo et al. indicated that protein-energy 


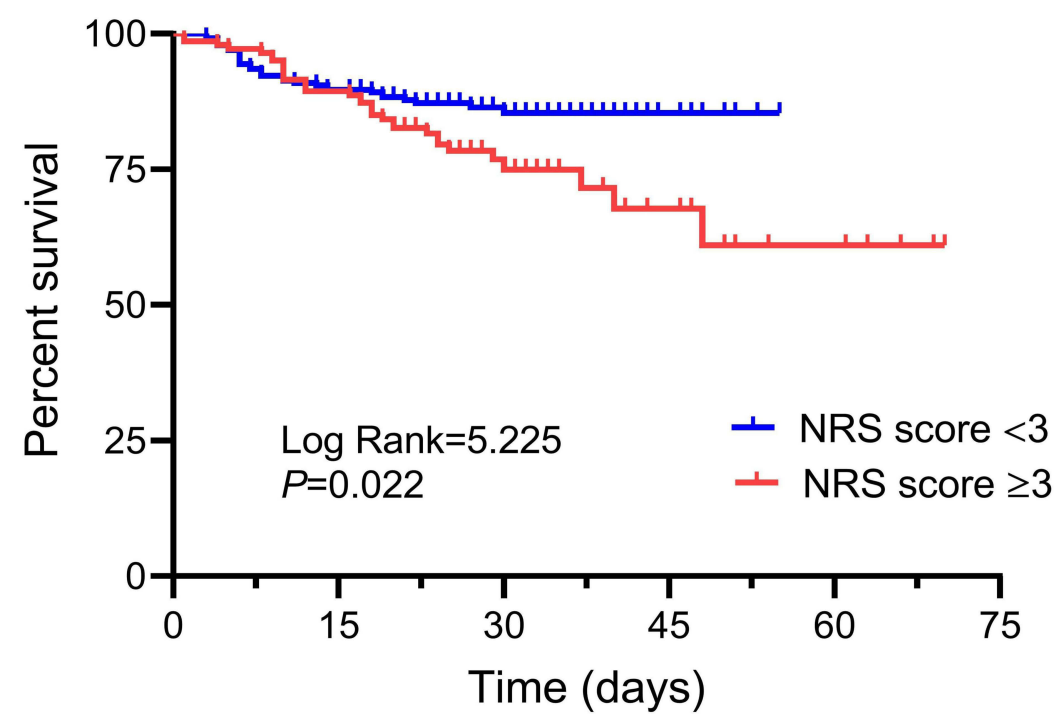

Figure 4 Kaplan-Meier survival estimates of sepsis mortality by nutritional risk screening score groups. Cumulative in-hospital survival was significantly lower in sepsis patients with an NRS score of $\geq 3$ (high nutritional risk group) than in those with an NRS score of $<3$ (low nutritional risk group) (76.6\% vs $86.6 \%$, Log Rank $=5.225, \mathrm{P}=0.022$ ).

malnutrition is a risk factor for sepsis and associated with poorer outcomes among patients with sepsis. ${ }^{35}$ However, there is a paucity of data relating to NRS-2002 for the septic population. A prospective observational study of patients from the ICU in Thailand indicated that being at risk based on NRS-2002 and enteral feeding or combination with parenteral nutrition were the nutrition factors affecting mortality. ${ }^{36}$ Another prospective cohort study suggested that timely nutritional support was beneficial to the patients at nutritional risk according to NRS-2002 by a lower complication rate or malnutrition-associated mortality. ${ }^{37}$ This was also demonstrated by Hersberger et al. ${ }^{20}$ Considering the easy operability of NRS-2002, clinicians can readily assess the nutritional risk of this population of patients on a dynamic basis. That would help to adjust the nutritional support programs for patients with sepsis.

In the present study, patients with a higher NRS score were older and had lower BMI, ALB, TP, and HB levels. Age is incorporated into the NRS score while weight loss is a feature of malnutrition. ALB, TP, and HB are commonly used indices of nutritional status but can be influenced by inflammation, cancer, trauma, or chronic diseases. ${ }^{38-40} \mathrm{We}$ found that advanced age and lower ALB levels were independent risk factors for poor prognosis in patients with sepsis. Old age is an independent risk factor for many diseases including sepsis; ${ }^{41,42}$ and older patients with immunosenescence, organ dysfunction, or other conditions tend to have worse prognosis. ${ }^{41,43}$ Similarly, recent studies have revealed that low ALB levels are an independent predictor of outcome in patients with sepsis. ${ }^{44,45}$ Low ALB levels disrupt physiologic homeostasis and suppress immunity and anti-inflammatory responses, leading to poor prognosis. ${ }^{46,47}$ Moreover, reduced ALB levels were found to be associated with an increased risk of malnutrition. ${ }^{48}$ Patients with sepsis, especially those with a high risk of malnutrition, should be paid more attention to ALB levels, and individualized timely nutritional intervention should be given when necessary. Increasing protein and energy intake can reduce mortality risk in critically ill patients with low body weight or nutritional status. ${ }^{49}$ Thus, nutritional assessment of patients with sepsis can guide treatment decisions and potentially improve clinical outcomes.

This study had several limitations. Firstly, as this was a single-center retrospective study, the results may not be generalizable and are susceptible to selection bias. Secondly, there was variability in the NRS scores in our cohort, which may have affected the accuracy of the analyses. Multicenter prospective studies are needed to validate our findings.

\section{Conclusion}

In conclusion, we found that older age and low ALB levels were independent risk factors for poor prognosis in sepsis patients; moreover, malnutrition (NRS score $\geq 3$ ) was significantly associated with increased in-hospital mortality. These results indicate that nutritional status as defined by NRS-2002 can effectively identify high-risk sepsis patients who may benefit from timely interventions such as nutritional support that can improve their clinical outcome. 
Table 2 Univariate and Multivariate Analysis of Poor Prognosis of Patients with Sepsis

\begin{tabular}{|c|c|c|c|c|c|c|}
\hline \multirow[t]{2}{*}{ Variables } & \multicolumn{3}{|c|}{ Univariate Analysis } & \multicolumn{3}{|c|}{ Multivariate Analysis } \\
\hline & HR & $95 \% \mathrm{Cl}$ & $P$ value & HR & $95 \% \mathrm{Cl}$ & $P$ value \\
\hline Gender(male) & 1.277 & $0.757-2.154$ & 0.358 & & & \\
\hline Age & 1.028 & $1.013-1.042$ & $<0.001$ & 1.020 & $1.005-1.036$ & 0.008 \\
\hline BMI & 1.024 & $0.95 I-I .102$ & 0.531 & & & \\
\hline ALB & 0.911 & $0.874-0.949$ & $<0.001$ & 0.924 & $0.885-0.966$ & $<0.001$ \\
\hline TP & 0.987 & $0.959-1.017$ & 0.403 & & & \\
\hline HB & 0.992 & $0.983-1.002$ & 0.099 & & & \\
\hline WBC & 0.998 & $0.985-1.011$ & 0.762 & & & \\
\hline LYM & 0.784 & $0.587-1.049$ & 0.101 & & & \\
\hline CRP & 1.004 & $1.00 \mathrm{I}-1.007$ & 0.014 & & & \\
\hline PCT & 1.004 & $0.995-1.013$ & 0.410 & & & \\
\hline NRS score & 1.284 & $1.094-1.506$ & 0.002 & & & \\
\hline SOFA score & 0.927 & $0.800-1.074$ & 0.312 & & & \\
\hline Nutrition support (yes) & 1.104 & $0.665-1.832$ & 0.701 & & & \\
\hline Early antibiotic treatment (yes) & 0.839 & $0.468-1.504$ & 0.555 & & & \\
\hline \multicolumn{7}{|l|}{ Major comorbidities } \\
\hline Hypertension (yes) & 1.867 & $0.585-5.954$ & 0.292 & & & \\
\hline Diabetes (yes) & 0.949 & $0.297-3.029$ & 0.930 & & & \\
\hline Kidney failure(yes) & 1.753 & $0.866-3.548$ & 0.119 & & & \\
\hline Source of infection & & & 0.639 & & & \\
\hline $\begin{array}{l}\text { Others or unexplained } \\
\text { sources }\end{array}$ & & & Reference & & & \\
\hline Respiratory infections & 0.883 & $0.446-1.750$ & 0.721 & & & \\
\hline Urinary infections & 1.236 & $0.508-3.009$ & 0.640 & & & \\
\hline Biliary infections & 1.405 & $0.750-2.635$ & 0.289 & & & \\
\hline Bloodstream infections & 1.054 & $0.306-3.630$ & 0.933 & & & \\
\hline
\end{tabular}

Abbreviations: BMI, body mass index; ALB, albumin; TP, total protein; HB, hemoglobin; WBC: white blood cell count; LYM, lymphocyte count; CRP, C-reactive protein; PCT, procalcitonin; NRS, nutritional risk screening; SOFA, sequential organ failure assessment.

\section{Availability of Supporting Data}

Authors can confirm all relevant data are included in the article and materials are available on request from the authors.

\section{Ethics Approval and Consent to Participate}

This retrospective study was approved by the Institutional Review Board/Independent Ethics Committee of Nanfang Hospital of Southern Medical University, and the need for informed consent was waived since all data were anonymized before analysis. Patient privacy and confidentiality of data were maintained in accordance with the Declaration of Helsinki.

\section{Funding}

There is no funding to report.

\section{Disclosure}

Qiqing Gao and Yao Cheng are co-first authors for this study. The authors declare that they have no conflicts of interest. 


\section{References}

1. Finfer S, Machado FR. The global epidemiology of sepsis. Does it matter that we know so little? Am J Respir Crit Care Med. 2016;193 (3):228-230. doi:10.1164/rccm.201510-1976ED

2. Jawad I, Luksic I, Rafnsson SB. Assessing available information on the burden of sepsis: global estimates of incidence, prevalence and mortality. $J$ Glob Health. 2012;2(1):10404. doi:10.7189/ jogh.02.010404

3. Dugani S, Veillard J, Kissoon N. Reducing the global burden of sepsis. CMAJ. 2017;189(1):E2-E3. doi:10.1503/cmaj.160798

4. Rudd KE, Johnson SC, Agesa KM, et al. Global, regional, and national sepsis incidence and mortality, 1990-2017: analysis for the Global Burden of Disease Study. Lancet. 2020;395(10219):200-211. doi:10.1016/S0140-6736(19)32989-7

5. Kaukonen KM, Bailey M, Suzuki S, Pilcher D, Bellomo R. Mortality related to severe sepsis and septic shock among critically ill patients in Australia and New Zealand, 2000-2012. JAMA. 2014;311 (13):1308-1316. doi:10.1001/jama.2014.2637

6. Yende S, Austin S, Rhodes A, et al. Long-Term quality of life among survivors of severe sepsis: analyses of two international trials. Crit Care Med. 2016;44(8):1461-1467. doi:10.1097/CCM.00000 00000001658

7. Paoli CJ, Reynolds MA, Sinha M, Gitlin M, Crouser E. Epidemiology and costs of sepsis in the United States-An analysis based on timing of diagnosis and severity level. Crit Care Med. 2018;46(12):1889-1897. doi:10.1097/CCM.0000000000003342

8. Gadre SK, Shah M, Mireles-Cabodevila E, Patel B, Duggal A. Epidemiology and predictors of 30-Day readmission in patients with sepsis. Chest. 2019;155(3):483-490. doi:10.1016/j.chest.20 18.12 .008

9. Rhodes A, Evans LE, Alhazzani W, et al. Surviving sepsis campaign: international guidelines for management of sepsis and septic shock: 2016. Intensive Care Med. 2017;43(3):304-377. doi:10.1007/s00134017-4683-6

10. Robinson MK, Mogensen KM, Casey JD, et al. The relationship among obesity, nutritional status, and mortality in the critically ill. Crit Care Med. 2015;43(1):87-100. doi:10.1097/CCM.0000 000000000602

11. Mogensen KM, Robinson MK, Casey JD, et al. Nutritional status and mortality in the critically ill. Crit Care Med. 2015;43(12):2605-2615. doi:10.1097/CCM.0000000000001306

12. Mira JC, Gentile LF, Mathias BJ, et al. Sepsis pathophysiology, chronic critical illness, and persistent Inflammation-Immunosuppression and catabolism syndrome. Crit Care Med. 2017;45(2):253-262. doi:10.1097/CCM.0000000000002074

13. Pepper DJ, Demirkale CY, Sun J, et al. Does Obesity Protect Against Death in Sepsis? A Retrospective Cohort Study of 55,038 Adult Patients. Crit Care Med. 2019;47(5):643-650. doi:10.1097/ CCM.0000000000003692

14. Pepper DJ, Sun J, Welsh J, Cui X, Suffredini AF, Eichacker PQ. Increased body mass index and adjusted mortality in ICU patients with sepsis or septic shock: a systematic review and meta-analysis. Crit Care. 2016;20(1):181. doi:10.1186/s13054-016-1360-z

15. Zhao Y, Li Z, Yang T, Wang M, Xi X. Is body mass index associated with outcomes of mechanically ventilated adult patients in intensive critical units? A systematic review and meta-analysis. PLoS One. 2018;13(6):e0198669. doi:10.1371/journal.pone.0198669

16. Karampela I, Chrysanthopoulou E, Christodoulatos GS, Dalamaga M. Is there an obesity paradox in critical illness? Epidemiologic and metabolic considerations. Curr Obes Rep. 2020;9(3):231-244. doi:10.1007/s13679-020-00394-x

17. Kondrup J, Allison SP, Elia M, Vellas B, Plauth M. ESPEN guidelines for nutrition screening 2002. Clin Nutr. 2003;22(4):415-421. doi:10.1016/s0261-5614(03)00098-0
18. Mcclave SA, Taylor BE, Martindale RG, et al. Guidelines for the provision and assessment of nutrition support therapy in the adult critically ill patient: society of critical care medicine (SCCM) and American society for parenteral and enteral nutrition (A.s.p.e.n.). JPEN J Parenter Enteral Nutr. 2016;40(2):159-211. doi:10.1177/ 0148607115621863

19. Kyle UG, Kossovsky MP, Karsegard VL, Pichard C. Comparison of tools for nutritional assessment and screening at hospital admission: a population study. Clin Nutr. 2006;25(3):409-417. doi:10.1016/j. clnu.2005.11.001

20. Hersberger L, Bargetzi L, Bargetzi A, et al. Nutritional risk screening (NRS 2002) is a strong and modifiable predictor risk score for short-term and long-term clinical outcomes: secondary analysis of a prospective randomised trial. Clin Nutr. 2020;39(9):2720-2729. doi:10.1016/j.clnu.2019.11.041

21. Sorensen J, Kondrup J, Prokopowicz J, et al. EuroOOPS: an international, multicentre study to implement nutritional risk screening and evaluate clinical outcome. Clin Nutr. 2008;27(3):340-349. doi:10.1016/j.clnu.2008.03.012

22. Sanson G, Sadiraj M, Barbin I, et al. Prediction of early- and long-term mortality in adult patients acutely admitted to internal medicine: NRS-2002 and beyond. Clin Nutr. 2020;39 (4):1092-1100. doi:10.1016/j.clnu.2019.04.011

23. Cavaillon JM, Singer M, Skirecki T. Sepsis therapies: learning from 30 years of failure of translational research to propose new leads. Embo Mol Med. 2020;12(4):e10128. doi:10.15252/emmm.201810128

24. De Waele E, Malbrain M, Spapen H. Nutrition in sepsis: a Bench-toBedside review. Nutrients. 2020;12(2):395. doi:10.3390/nu12020395

25. Singer M, Deutschman CS, Seymour CW, et al. The third international consensus definitions for sepsis and septic shock (Sepsis-3). JAMA. 2016;315(8):801-810. doi:10.1001/jama.2016.0287

26. Kondrup J, Rasmussen HH, Hamberg O, Stanga Z. Nutritional risk screening (NRS 2002): a new method based on an analysis of controlled clinical trials. Clin Nutr. 2003;22(3):321-336. doi:10.1016/ s0261-5614(02)00214-5

27. Englert JA, Rogers AJ. Metabolism, metabolomics, and nutritional support of patients with sepsis. Clin Chest Med. 2016;37(2):321-331. doi:10.1016/j.ccm.2016.01.011

28. Elke G, Kott M, Weiler N. When and how should sepsis patients be fed? Curr Opin Clin Nutr Metab Care. 2015;18(2):169-178. doi:10.1097/MCO.0000000000000151

29. Mickiewicz B, Vogel HJ, Wong HR, Winston BW. Metabolomics as a novel approach for early diagnosis of pediatric septic shock and its mortality. Am J Respir Crit Care Med. 2013;187(9):967-976. doi:10.1164/rccm.201209-1726OC

30. Rogers AJ, Mcgeachie M, Baron RM, et al. Metabolomic derangements are associated with mortality in critically ill adult patients. PLoS One. 2014;9(1):e87538. doi:10.1371/journal.pone.0087538

31. Alberda C, Gramlich L, Jones N, et al. The relationship between nutritional intake and clinical outcomes in critically ill patients: results of an international multicenter observational study. Intensive Care Med. 2009;35(10):1728-1737. doi:10.1007/s00134-009-1567-4

32. Singer P, Doig GS, Pichard C. The truth about nutrition in the ICU. Intensive Care Med. 2014;40(2):252-255. doi:10.1007/s00134-0133162-y

33. Coopersmith CM, De Backer D, Deutschman CS, et al. Surviving sepsis campaign: research priorities for sepsis and septic shock. Intensive Care Med. 2018;44(9):1400-1426. doi:10.1007/s00134-018-5175-z

34. Dizdar OS, Baspinar O, Kocer D, et al. Nutritional risk, micronutrient status and clinical outcomes: a prospective observational study in an infectious disease clinic. Nutrients. 2016;8(3):124. doi:10.3390/ nu8030124

35. Adejumo AC, Akanbi O, Pani L. Protein energy malnutrition is associated with worse outcomes in Sepsis-A nationwide analysis. $J$ Acad Nutr Diet. 2019;119(12):2069-2084. doi:10.1016/j. jand.2019.04.019 
36. Auiwattanakul S, Chittawatanarat K, Chaiwat O, et al. Effects of nutrition factors on mortality and sepsis occurrence in a multicenter university-based surgical intensive care unit in Thailand (THAI-SICU study). Nutrition. 2019;58:94-99. doi:10.1016/j.nut.2018.06.021

37. Jie B, Jiang ZM, Nolan MT, et al. Impact of nutritional support on clinical outcome in patients at nutritional risk: a multicenter, prospective cohort study in Baltimore and Beijing teaching hospitals. Nutrition. 2010;26(11-12):1088-1093. doi:10.1016/j.nut.2009.08.027

38. Cruz-Jentoft AJ, Kiesswetter E, Drey M, Sieber CC. Nutrition, frailty, and sarcopenia. Aging Clin Exp Res. 2017;29(1):43-48. doi:10.1007/s40520-016-0709-0

39. Perez-Ros P, Vila-Candel R, Lopez-Hernandez L, Martinez-Arnau FM. Nutritional status and risk factors for frailty in Community-Dwelling older people: a Cross-Sectional study. Nutrients. 2020;12(4):1041. doi:10.3390/nu12041041

40. Zhang Z, Pereira SL, Luo M, Matheson EM. Evaluation of blood biomarkers associated with risk of malnutrition in older adults: a systematic review and Meta-Analysis. Nutrients. 2017;9(8):829. doi: $10.3390 /$ nu9080829

41. Martin GS, Mannino DM, Moss M. The effect of age on the development and outcome of adult sepsis. Crit Care Med. 2006;34 (1):15-21. doi:10.1097/01.ccm.0000194535.82812.ba

42. Yang Y, Yang KS, Hsann YM, Lim V, Ong BC. The effect of comorbidity and age on hospital mortality and length of stay in patients with sepsis. J Crit Care. 2010;25(3):398-405. doi:10.1016/ j.jcrc.2009.09.001

43. Clifford KM, Dy-Boarman EA, Haase KK, Maxvill K, Pass SE, Alvarez CA. Challenges with diagnosing and managing sepsis in older adults. Expert Rev Anti Infect Ther. 2016;14(2):231-241. doi:10.1586/14787210.2016.1135052
44. Seo MH, Choa M, You JS, et al. Hypoalbuminemia, low base excess values, and tachypnea predict 28-Day mortality in severe sepsis and septic shock patients in the emergency department. Yonsei Med J. 2016;57(6):1361-1369. doi:10.3349/ymj.2016.57.6.1361

45. Yin M, Si L, Qin W, et al. Predictive value of serum albumin level for the prognosis of severe sepsis without exogenous human albumin administration: a prospective cohort study. J Intensive Care Med. 2018;33(12):687-694. doi:10.1177/0885066616685300

46. Lee JH, Kim J, Kim K, et al. Albumin and C-reactive protein have prognostic significance in patients with community-acquired pneumonia. J Crit Care. 2011;26(3):287-294. doi:10.1016/j.jcrc.2010.10.007

47. Vincent JL, Dubois MJ, Navickis RJ, Wilkes MM. Hypoalbuminemia in acute illness: is there a rationale for intervention? A meta-analysis of cohort studies and controlled trials. Ann Surg. 2003;237 (3):319-334. doi:10.1097/01.SLA.0000055547.93484.87

48. Demir MV, Tamer A, Cinemre H, Uslan I, Yaylaci S, Erkorkmaz U. Nutritional status and laboratory parameters among internal medicine inpatients. Niger J Clin Pract. 2015;18(6):757-761. doi:10.4103/ 1119-3077.158145

49. Compher C, Chittams J, Sammarco T, Higashibeppu N, Higashiguchi T, Heyland DK. Greater nutrient intake is associated with lower mortality in western and eastern critically ill patients with low BMI: a multicenter, multinational observational study. JPEN J Parenter Enteral Nutr. 2019;43(1):63-69. doi:10.1002/jpen.1180
Infection and Drug Resistance

\section{Publish your work in this journal}

Infection and Drug Resistance is an international, peer-reviewed openaccess journal that focuses on the optimal treatment of infection (bacterial, fungal and viral) and the development and institution of preventive strategies to minimize the development and spread of resistance. The journal is specifically concerned with the epidemiology of
Dovepress

antibiotic resistance and the mechanisms of resistance development and diffusion in both hospitals and the community. The manuscript management system is completely online and includes a very quick and fair peerreview system, which is all easy to use. Visit http://www.dovepress.com/ testimonials.php to read real quotes from published authors. 